\title{
ANALISIS PEMBERIAN KREDIT PADA PT.BANK PERKREDITAN RAKYAT SAMUDERA PAINAN
}

\author{
Dian Susanti, Romi Susanto \\ Akademi Keuangan dan Perbankan "Pembangunan" Padang \\ diansusanti548@gmail.com
}

\begin{abstract}
The purpose of this study was to determine the implementation of credit at PT. Bank Perkreditan Rakyat Samudera Painan. The research method used is a qualitative data analysis method. The result described how credit distribution, credit growth, and credit collectibillity. The result of this study found that the granting of credit at PT. Bank Perkreditan Rakyat Samudera Painan has several stages namely, credit application stage, credit analysis stage, credit decision stage, credit contract stage and credit disbursement stage.
\end{abstract}

Keywords: Bank, Credit

\section{PENDAHULUAN}

Bank merupakan lembaga Financial intermediary yang membantu kelancaran sistem pembayaran, dan sebagai lembaga yang menjadi sarana pelaksanaan kebijakan pemerintah yaitu kebijakan moneter (Margaretha \& Setiyaningrum, 2011). Pengertian lain Bank adalah lembaga yang kegiatan utamanya menghimpun dana dari masyarakat dan menyalurkan kembali ke masyarakat (Herman \& Widayati, 2019). Pada saat ini salah satu tempat masyarakat meminjam uang ialah di bank yang digunakan untuk kebutuhan pribadi, membuka usaha dan mengembangkan usaha. Terlebih pada saat covid-19 ini membuat beberapa masyarakat kehilangan mata pencahariannya maupun berkurangnya pendapatan perekonomian bahkan ada yang kehilangan pekerjaanya karena di PHK. Hal-hal inilah yang menyebabkan masyarakat meminjam uang dalam bentuk kredit. Semua bank yang terdaftar di Indonesia sudah djamin oleh Lembaga Penjamin Simpanan (LPS) jadi masyarakat tidak perlu takut menimpan uang di bank. Bank sendiri terbagi atas 2 jenis : 1. Bank Umum, 2. Bank BPR.

Menurut (Kasmir, 2014) Bank umum adalah yang menjalankan kegiatan usaha secara konvensional atau berdasarkan prinsip syariah yang dalam kegiatannya tidak memberikan jasa lalu lintas pembayaran. Menurut (Andriani \& Susanto, 2017) bank menerima simpanan dalam bentuk tabungan dan deposito, penyaluran dana dalam bentuk kredit. Menurut (Yaumil \& Susanto, 2019) Kegiatan Bank BPR jauh lebih sempit dibandingkan dengan kegiatan bank umum.

PT. Bank Perkreditan Rakyat Samudera Painan adalah suatu lembaga keuangan dengan kegiatan simpan pinjam dengan tujuan membantu masyarakat yang membutuhkan dana untuk usahanya ataupun keperluan lain di Daerah Painan dan sekitarnya di Kabupaten Pesisir Selatan. Pada BPR Samudera ada dua jenis 
Produk bank yaitu Produk simpanan berupa tabungan dan deposito, serta Produk Penyaluran dana berupa Kredit. dalam memberikan kredit kepada calon debitur,bank harus berhati-hati, teliti dan cermat serta harus memperhatikan aspek-aspek penting lainnya dalam pemberian kredit seperti adanya jaminan (agunan), keaslian dokumen-dokumen, SID (sistem informasi debitur) serta syarat-syarat lainnya yang akan digunakan sebagai bahan pertimbangan oleh direktur/pimpinan bank untuk pengambilan keputusan dalam pemberian kredit (Oktavia zalpi \& Susanto, 2018). Dalam Penyaluran kredit kepada masyarakat bank menggunakan prinsip 3T yaitu Tepat waktu, Tepat sasaran, dan Tepat Jumlah (Sanjaya \& Marlius, 2017). Berikut ini adalah data perkembangan kredit PT.BPR Samudera Painan selama 5 tahun.

\section{Tabel 1}

\begin{tabular}{cccc}
\multicolumn{4}{c}{ Perkembangan Kredit PT. Bank Perkreditan Rakyat Samudera Painan } \\
Tahun 2015 - 2019 (Dalam Rupiah)
\end{tabular}

Sumber: PT.Bank Perkreditan Rakyat Samudera Painan.

Dari tabel 1 diatas dapat dilihat bahwa setiap tahunnya PT. Bank Perkreditan Rakyat Samudera Painan mengalami kenaikan Nominal Kredit dan Nasabah Kredit kecuali ditahun 2017 mengalami sedikit penurunan dari tahun sebelumnya, yang berarti mengalami kemajuan dan peningkatan setiap tahunnya. untuk Jumlah Kredit Bermasalah juga mengalami penurunan kecuali pada tahun 2016.

\section{METODE PENELITIAN}

\section{Metode Pengumpulan Data}

1. Riset Kepustakaan (Library Research)

Yaitu penelitian yang dilakukan di perpustakaan dengan membaca referensi penelitian terdahulu. Membaca buku-buku, artikel-artikel serta data yang telah dipublikasi yang berhubungan dengan objek penelitian.

2. Riset Lapangan (field research)

Penelitian langsung pada objek terkait dengan meneliti hasil data yang diperoleh. Penelitian ini dapat membantu penulis dalam melengkapi data yang diperlukan, dengan kegiatan yang dilakukan mewawancarai pihakpihak yang bersangkutan atau pihak perusahaan, instansi yang terkait.

\section{Metode Analisis Data}

Penulis menggunakan metode analisis data kualitatif yaitu sebagai metode penelitian yang menjelaskan berupa gambaran mengenai kualitas objek penelitian yang bersangkutan. 


\section{HASIL DAN PEMBAHASAN}

PT. Bank Perkreditan Rakyat Samudera Painan menjadi lembaga yang membantu masyarakat khususnya untuk wilayah Pesisir Selatan dalam membuka usaha maupun mengembangkan usaha dalam bentuk kredit. Menurut (Astiko, 1996) kredit adalah penyedian uang atau tagihan yang dapat dipersamakan dengan itu yang mana pihak peminjam wajib melunasi utang sesuai jangka wtu yang telah ditentukan. suatu lembaga yang memiliki kemampuan pembayaran dengan jangka waktu yang telah ditetapkan dan disepakati (Darussalam, 2013).

Pemberian kredit kepada calon debitur haruslah berhati-hati, agar tidak tidak terjadinya resiko kredit dikemudian hari. Ada beberapa tahapan pemberian kredit yang dilakukan oleh PT. BPR Samudera Painan, yaitu tahap permohonan kredit, tahap analisis kredit, tahap keputusan kredit, tahap akad kredit dan tahap pencairan kredit.

Analisis Pemberian kredit tersebut bertujuan untuk memperoleh keyakinan, kemampuan dan kemauan calon debitur untuk memenuhi kewajibannya terhadap bank dengan tepat waktu, baik pembayaran angsuran beserta bunganya .

\section{Jenis-Jenis Kredit}

Adapun beberapa jenis kredit, yaitu :

1. Jenis Kredit berdasarkan tujuan penggunaan
a. Kredit Konsumtif
b. Kredit Produktif

2. Jenis Kredit Berdasarkan Kegunaanya

a. Kredit investasi

b. Kredit modal kerja

3. Kredit berdasarkan jangka waktu
a. Kredit Jangka Panjang
b. Kredit Jangka Menengah
c. Kredit Jangka Pendek

4. Kredit menurut jaminannya
a. Secured loans
b. Unsecured loans

\section{Tujuan dan Fungsi Kredit}

1. Tujuan Kredit
a. Untuk mencari keuntungan
b. Membantu usaha debitur
c. Membantu Pemerintah

2. Fungsi Kredit

a. Meningkatkan daya guna uang

b. Meningkatkan peredaran lalu lintas uang

c. Sebagai alat stabilitas ekonomi

\section{Prinsip Pemberian Kredit}

Menurut (Yasman \& Afriyeni, 2019) Prinsip pemberian kredit yang sering dipakai didunia perbankan terdiri dari Prinsip 5C, 7P, 3R. 


\section{Tingkat Kolektibilitas Kredit}

Kolektibilitas kredit adalah keadaan yang menunjukan kemampuan debitur dalam kredit yang diberikan oleh bank, Kolektibilitas kredit dalam suatu bank, terbagi atas :

1. Kredit Lancar

2. Kredit Dalam perhatian khusus

3. Kredit Kurang lancar

4. Kredit Diragukan

5. Kredit Macet

\section{Kredit Bermasalah}

Kredit Bermasalah adalah suatu keadaan dimana perjanjian kredit yang sebelumnya sudah disepakati namun dilanggar oleh salah satu pihak (wanprestasi). Kredit bermasalah disebabkan oleh dua faktor, yaitu : Faktor eksternal dan faktor internal.

\section{Prosedur Pemberian Kredit}

Prosedur pemberian kredit yaitu proses yang dilaksanakan petugas bank yang berhubungan dengan kredit. Langkah ini bertujuan agar kredit yang disalurkan kepada masyarakat dapat berjalan dengan lancar, tepat waktu, dan berguna bagi kedua belah pihak yaitu debitur dan kreditur. (Setyawan, 2017). Secara umum ada beberapa tahapan prosedur pemberian kredit yang ada pada PT. BPR Samudera Painan adalah sebagai berikut :

1. Tahap Permohonan Kredit

2. Tahap Analisis Kredit

3. Tahap Keputusan Kredit

4. Tahap Akad Kredit

5. Tahap Pencairan Kredit

\section{Perkembangan Nominal Kredit}

Perkembangan nominal kredit pada PT. Bank Perkreditan Rakyat Samudera Painan dapat dilihat melalui tabel dibawah ini, sebagai berikut :

Tabel 2

Perkembangan Nominal Kredit pada PT. BPR Samudera Painan Tahun 2015-2019

\begin{tabular}{cccc}
\hline Tahun & Nominal kredit & Perkembangan & Naik/Turun \\
\hline 2015 & 7.037 .318 .811 & $0 \%$ & - \\
2016 & 9.977 .353 .569 & $41,78 \%$ & Naik \\
2017 & 10.258 .867 .444 & $2,82 \%$ & Naik \\
2018 & 15.266 .514 .142 & $48,81 \%$ & Naik \\
2019 & 17.768 .835 .686 & $16,39 \%$ & Naik \\
\hline
\end{tabular}

Sumber : PT. Bank Perkreditan Rakyat Samudera Painan

Berdasarkan tabel diatas, diketahui bahwa Jumlah Nominal kredit yang ada pada PT. BPR Samudera Painan mengalami peningkatan dari tahun 20152019. Hal ini dikarenakan pihak bank selalu memperbaiki kinerja keuangannya. Dengan adanya nominal kredit yang meningkat, akan memperbaiki keuangan bank tersebut, dan akan mendapatkan laba serta menjadikan sebuah pencapaian yang sangat baik untuk PT. BPR Samudera Painan. 


\section{Perkembangan Nasabah Kredit}

Perkembangan Nasabah kredit yang ada pada PT. Bank Perkreditan Rakyat Samudera Painan dapat dilihat pada tabel dibawah ini :

Tabel 3

Perkembangan Nasabah Kredit PT. BPR Samudera Painan

Tahun 2015 - 2019

\begin{tabular}{cccc}
\hline Tahun & Nasabah Kredit & Perkembangan & Naik/ Turun \\
\hline 2015 & 461 & $0 \%$ & - \\
2016 & 484 & $4,99 \%$ & Naik \\
2017 & 483 & $-0,21 \%$ & Turun \\
2018 & 512 & $6,00 \%$ & Naik \\
2019 & 527 & $2,93 \%$ & Naik \\
\hline
\end{tabular}

Sumber : PT. Bank Perkreditan Rakyat Samudera Painan.

Dilihat dari jumlah nasabah kredit yang terjadi dari tahun 2015 sampai dengan tahun 2019 mengalami peningkatan dan penurunan jumlah nasabah kredit. Peningkatan jumlah nasabah kredit akan memberikan laba bagi pihak bank dan memperbaiki pertumbuhan ekonomi. Apabila Permintaan kredit menurun maka akan menurunkan laju pertumbuhan pembangunan yang akan berdampak terhadap penurunan perekonomian nasional.

\section{Kredit Bermasalah dan Cara Penyelesaian}

\section{Kredit Bermasalah}

Kredit bermasalah yang ada pada PT. Bank Perkreditan Rakyat Samudera Painan adalah sebagai berikut :

Tabel 4

Perkembangan Kredit Bermasalah PT. BPR Samudera Painan

Tahun 2015-2019

\begin{tabular}{cccc}
\hline Tahun & Kredit Bermasalah & Perkembangan & Naik/Turun \\
\hline 2015 & 15 & $0 \%$ & - \\
2016 & 25 & $66,67 \%$ & Naik \\
2017 & 19 & $-24,00 \%$ & Turun \\
2018 & 15 & $-21,05 \%$ & Turun \\
2019 & 5 & $-66,67 \%$ & Turun \\
\hline
\end{tabular}

Sumber: PT. Bank Perkreditan Rakyat Samudera Painan

Dari analisa tersebut diketahui bahwa Jumlah debitur bermasalah dan pertumbuhannya tidak menentu setiap tahun, untuk hal ini diharuskan PT. BPR Samudera Painan untuk mengurangi resiko kredit bermasalah ini, karena apabila dibiarkan maka akan berdampak pada keuangan bank. Kemudian untuk memperkecil dan mengurangi jumlah kredit bermasalah maka solusi yang dilakukan PT. BPR Samudera Painan adalah memberikan penanganan terhadap debitur bermasalah yang diawali secara kekeluargaan, kemudian melakukan restructuring dan jika tetap tidak bisa membayar dan pihak bank akan memberikan surat peringatan (SP) kepada debitur tersebut, surat tersebut berisi agar debitur mampu untuk melunasinya. Namun jika tidak, dan hingga dikeluarkannya SP sebanyak 3 kali dengan perbedaan waktu pemberian 2 sampai 3 bulan, maka pihak bank akan memprosesnya yaitu dengan menyita agunan/jaminan yang sebelumnya dijadikan jaminan atas pinjaman kredit untuk di 
lelang, sebagai pelunasan utang kredit tersebut. Untuk sisa hasil lelangan dikembalikan kepada pihak nasabah kredit.

\section{Penyebab Kredit Bermasalah}

Adapun beberapa faktor penyebab terjadinya Kredit bermasalah Pada PT. BPR Samudera Painan, Yaitu sebagai berikut :

1. Faktor Eksternal (Dari Luar Perusahaan)

a. Adanya unsur kesengajaan dari nasabah untuk tidak melunasi utangnya

b. Faktor ekonomi yaitu nasabah ingin membayar namun tidak memiliki cukup uang untuk melunasi utangnya.

c. Adanya penyalahgunaan dalam penggunaan kredit.

d. Perubahan kebijakan dan peraturan pemerintah yang berdampak pada usaha debitur.

2. Faktor Internal (Dari Dalam Perusahaan)

a. Kurangnya ketelitian dan kehati-hatian dari pihak PT. BPR Samudera Painan dalam melakukan pengawasan terhadap nasabah kredit.

b. Adanya kolusi antara pejabat bank dengan calon debitur.

c. Tidak dilakukannya on the spot/wawancara sesuai dengan ketentuan yang telah ditetapkan.

d. Adanya campur tangan dari pihak terkait.

\section{Penyelesaian Kredit Bermasalah}

Penyelesaian kredit bermasalah dilakukan dengan dua faktor, yaitu penyelesaian faktor eksternal dan penyelesaian faktor internal, yaitusebagai berikut :

\section{Penyelesaian faktor Eksternal}

1. Peringatan Secara Lisan

2. Restructuring dan Rescheduling

3. Peringatan Tertulis

4. Penarikan Jaminan (lelang)

\section{Penyelesaian Faktor Internal}

1. Peringatan Tertulis kepada karyawan

2. Penurunan Jabatan

3. Mutasi

\section{SIMPULAN}

Berdasarkan uraian yang telah dikembangkan pada bab-bab sebelumnya, maka penulis dapat menyampakan beberapa kesimpulan mengenai analisis pemberian kredit pada PT. Bank Perkreditan Rakyat Samudera Painan, sebagai berikut :

1. Pelaksanaan pemberian kredit pada PT. Bank Perkreditan Rakyat Samudera Painan dimulai dari Tahap Permohonan Kredit, Tahap Analisis Kredit, Tahap Keputusan Kredit, Tahap Akad Kredit dan Tahap Pencairan Kredit.

2. Perkembangan Nominal Kredit dan Nasabah Kredit pada PT. Bank Perkreditan Rakyat Samudera Painan mengalami peningkatan yang baik, hal ini disebabkan oleh adanya kinerja bank yang cukup kuat untuk 
memperbaiki kredit bank dalam mengenalkan kredit kepada masyarakat banyak. Jika kredit yang diberikan debitur semakin banyak, maka akan semakin baik pula keuangan yang ada pada bank tersebut. Kemudian, semakin banyak kredit yang disalurkan maka akan semakin baik pula perekonomian suatu negara.

3. Kredit bermasalah disebabkan oleh dua faktor, yaitu faktor eksternal dan faktor internal. Adapun upaya penyelesaian faktor eksternal yaitu dengan melakukan peringatan secara lisan, rescheduling dan restructuring, peringatan tertulis dan penarikan jaminan (lelang). Untuk penyelesaian faktor internal yaitu dengan melakukan peringatan tertulis, Penurunan jabatan, dan mutasi.

\section{UCAPAN TERIMAKASIH}

Dengan menyebut nama Allah SWT yang maha pengasih lagi maha penyayang, penulis mengucapkan puji dan syukur atas kehadirat-Nya, yang telah melimpahkan rahmat dan hidayahnya kepada saya. Penulis juga ingin menyampaikan terimakasih yang tak terhingga kepada pihak yang telah memberikan kesempatan kepada penulis untuk melakukan peneitian ini.

\section{DAFTAR PUSTAKA}

Andriani, B., \& Susanto, R. (2017). Pengawasan Kredit PT. BPR Ophir Pasaman Barat. 1-12.

Amelia, L., \& Marlius, D. (2018). Pengendalian Kredit Dalam Upaya Menciptakan Bank Yang Sehat Pada PT. Bank Pembangunan Daerah Sumatera Barat Cabang Utama Padang. https://doi.org/10.31227/osf.io/kpc64

Alanshari, F., \& Marlius, D. (2018). Prosedur Pemberian Kredit KPR Pada PT. Bank Tabungan Negara (Persero) TBK Cabang Pembantu Bukittinggi. https://doi.org/10.31227/osf.io/rsfhc

Astiko. (1996). Manajemen Perkreditan (A. Offset (ed.)).

Asyari, A., \& Marlius, D. (2021). Proses Penyelesaian Kredit Bermasalah Pada PT. BPD Sumatera Barat Cabang Pasar Raya Padang. https://doi.org/10.31219/osf.io/3hfcr

Darussalam, O. (2013). Faktor-Faktor Penyebab Kredit Bermasalah di PT. Bank Sulut Cabang Utama Manado. EMBA, 1(4), 69-77.

Herman, U., \& Widayati, R. (2019). Penyelesaian Kredit Bermasalah Pada PT. Bank Perkreditan Rakyat (BPR) Nagari Kasang. 1-14.

Kasmir, D. \&. (2014). Dasar-Dasar Perbankan. PT. Raja Grafindo Persada. 
Margaretha, F., \& Setiyaningrum, D. (2011). Pengaruh Resiko, Kualitas Manajemen, Ukuran dan Likuiditas Bank Terhadap Capital Adequacy Ratio Bank-Bank yang Terdaftar di Bursa Efek Indonesia. Jurnal akuntansi dan keuangan, 13, 47-56.

Oktavia zalpi, S., \& Susanto, R. (2018). Analisis Pemberian Kredit Pada PT. Bank Perkreditan Rakyat Samudera Painan. 1-10.

Shanjaya, A. R., \& Marlius, D. (2017). Peranan Laporan Keuangan Dalam Kebijaksanaan Pemberian Kredit Kepada Calon Nasabah Pada PT. BPR Batang Kapas. https://doi.org/10.31227/osf.io/uxmg6

Setyawan, A. (2017). Analisis prosedur pemberian kredit pada PT. BPR ARTHA SAMUDRA. Simki-Economic, 01(08).

Yasman, R., \& Afriyeni. (2019). Prosedur Pemberian Kredit pada PT. Bank Perkreditan Rakyat (BPR) Jorong Kampung Tengah (JKT) Pariaman Cabang Padang. 7, 1-9.

Yaumil, R. S., \& Susanto, R. (2019). Aktivitas Penghimpunan Dana Pada PT. Bank Pembangunan Daerah Sumatera Barat Cabang Painan. 1-14. 